\title{
Trends of hydroclimatic intensity in Colombia
}

\author{
Oscar Mesa ${ }^{1, *}$, Viviana Urrea ${ }^{1}$ and Andrés Ochoa ${ }^{1}$ \\ ${ }^{1}$ Departamento de Geociencias y Medio Ambiente, Universidad Nacional de \\ Colombia, Medellín, Colombia \\ Correspondence*: \\ Oscar Mesa, Departamento de Geociencias y Medio Ambiente, Universidad \\ Nacional de Colombia, Carrera 80 \# 64-223, 050041 Medellín, Colombia \\ ojmesa@unal.edu.co
}

\section{ABSTRACT}

Prediction of changes in precipitation in upcoming years and decades caused by global climate change associated with the greenhouse effect, deforestation and other anthropic perturbations is a practical and scientific problem of high complexity and huge consequences. To advance toward this challenge we look at the daily historical record of all available rain gauges in Colombia to estimate an index of the intensity of the hydrologic cycle (Giorgi et al., 2011). The index is the product of precipitation intensity and dry spell length. Theoretical reasons indicate that global warming should lead to increasing trends in either one of the factors or both. Our results indicate that there is no clear picture, there are gauges with positive and negative significant trends, and most of the gauges do not show a significant trend. We present the geographic distribution of results within regions and concerning the elevation in the Andes Cordillera. Results seem to agree with previous reports of total annual precipitation trends.

\section{Keywords: Precipitation trends, Climate change, Colombia, Hydrologic cycle, dry spell length}

\section{INTRODUCTION}

Predicting the effect of climate change on Colombia's hydrology, more specifically on precipitation, is not a small matter. To illustrate, only in the electricity sector recent studies for the Mining and Energy Planning Unit Macías and Andrade (2014) estimate that the impacts of the decrease in precipitation imply an increase in annual investment of US\$ 290 million per year for the period 2013-2015.

But not only the impact is of magnitude, but the scientific problem of such prediction is also very complex, such models are not necessarily accurate. The focus of this work is the impact on precipitation, although global climate change impacts many more aspects such as temperature, sea level, coastal erosion, páramo ecosystem loss, vector-borne diseases, biodiversity, agriculture, and others.

Understanding the temporal-spatial variability of precipitation is a challenge of great importance due to the environmental, social, economic and cultural implications of the distribution of water resources in any country. On the other hand, the analysis of hydrologic processes under a climate change context, in addition to incorporating greater complexity to these processes, leads to the need to join efforts towards the understanding of national hydrology to manage the resource better. The broad objective of this work is to contribute to that challenging question, focusing on the use of precipitation information and mathematical and statistical techniques to identify and interpret evidence of climate change in Colombia. 
Given the complexity of rainfall fields and the tropical climate in the rough topography derived by the Andes cordillera, rainfall records in Colombia are generally scarce, both because of their quality, missing data, length of the records and spatial coverage. Therefore, it is a unique challenge for Hydrology to predict the impact of climate change over Colombia rainfall at spatial and temporal scales suitable for critical applications. Among those applications, one can mention the planning for the sustainable development of the territory and its hydraulic resources, disaster prevention. Some of the theoretical questions are a better knowledge of the influence of macro-climatic phenomena like El Niño-Southern Oscillation (ENSO). In turn, a better understanding may allow better predictions.

\section{PREVIOUS WORK}

This short review has two parts. First, we present the main results of previous studies about climate change impact on Colombian rainfall trends. Then we briefly show the general context of how global warming impact precipitation.

Various works describe the climatology of the precipitation in Colombia (Snow, 1976; Oster, 1979; Eslava, 1993; Mesa et al., 1997; Mejía et al., 1999). The central control is the passage, twice a year, of the Inter-Tropical Convergence Zone that marks the rainy seasons of April-May and September-November in the Andes, and the seasons with the lowest rainfall in December-February and June. -August. The spatial distribution is marked by the sources of humidity in the Caribbean, the Pacific, and the Amazon, by the topography and prevailing winds. The inter-annual variability is controlled mainly by the phenomenon of ENSO in the tropical Pacific (Poveda and Mesa, 1997; Poveda et al., 2011).

Several studies have found evidence of climate change in Colombia using various statistical techniques with different record lengths (e.g. Smith et al., 1996; Mesa et al., 1997; Quintana-Gomez, 1999; Vuille et al., 2003; Ochoa and Poveda, 2008; Pabón, 2009; Cantor and Ochoa, 2011; Cantor, 2011; Carmona and Poveda, 2014; Hurtado and Mesa, 2015). In summary, these studies identify increasing trends in mean and minimum temperature records in a significant number of stations. Besides, they find mixed trends in precipitation, with a similar percentage of stations for each trend and $20 \%$ without a statistically significant trend for the set of considered series of up to 40 years of records. For precipitation stations with longer records, the majority (63\%) shows an increasing trend and only $16 \%$ decreasing trend. A clear geographical pattern is not identified to locate areas with a particular trend, except in the Pacific plain that has the highest definite upward trend, explained by an increasing trend of the influence of moisture in the Pacific and the Chocó Jet.

These conclusions coincide with the IDEAM report, Mayorga et al. (2011), which analyzed 310 rainfall stations with monthly records in the period 1970-2010 using RCLIMDEX. This is a program developed by the $\mathrm{CCl} /$ CLIVAR working group (Climate and Ocean: Variability, Predictability and Change) part of the World Climate Research Program of the World Meteorological Organization and Unesco for the detection of climate change as a coordinated international effort to have indexes calculated with the same methodology that can be integrated internationally (Peterson, 2005). Of the 310 precipitation stations, $71 \%$ show increasing trend, seven $\%$ without trend, $22 \%$ decreasing trend. The conclusion related to the rising temperature is also confirmed, with an increase of $0.17 \mathrm{~K}$ per decade. It is essential to quote the report: " ... the generalized increase in precipitation in the country is noticeable, highlighting the north-western zone (Antioquia and Chocó), Vichada, the Piemonte de Putumayo and the island of Providencia, where the most significant increase. The opposite occurs on the island of San Andrés, on the eastern slope of the 
Eastern Cordillera (Arauca and Casanare) and in large areas of the Upper Cauca, where there is a decrease in precipitation. The largest decrease occurs in the south-west of the territory."

It is clear that the observed trends may be due to other causes besides increasing greenhouse gas global warming; deforestation and urbanization among others, not to mention observational issues.

Concerning the impact of deforestation, Salazar (2011) estimates through a numerical experiment that a possible drastic future change in coverage in the Amazon area would bring about a reduction in precipitation in Colombia of an order of magnitude of $300 \mathrm{~mm} / \mathrm{year}$.

The warming of the Colombian Andes has led to the complete extinction of eight tropical glaciers, and the six remaining snow-caps lose ice at accelerated rates (Rabatel et al., 2013). The páramos, unique and strategic ecosystems to supply water to several cities, including Bogotá and Medellín are also in danger by warming and other anthropogenic activities (Ruiz et al., 2008).

The heating means an increase of the air saturation vapor pressure according to the Clausius-Clapeyron equation. Overall, this increase is has been accompanied by an increase in evaporation and, therefore, in absolute humidity, to keep the relative humidity relatively constant (Stevens et al., 2013). A few series of tank evaporation and relative humidity confirm this observation for Colombia (Mesa et al., 1997). The consequences of this are essential to understanding the physical mechanisms associated with the impact of warming on precipitation and river flow.

Mesa et al. (1997) reports that a good part of the flow series in the Magdalena-Cauca basins have a decreasing trend. Recently, Carmona and Poveda (2014) confirm and reinforce this conclusion about the trends from their analysis of the same series with new years of observations and other series not analyzed in the initial work. The number of stations with a decreasing trend is higher than the number showing an increasing trend. The percentage that decreases varies from $61 \%$ to $100 \%$ depending on the length of the record, the first value for records of 25 years and the last for records over 50 years. Whereas, 0 to $34 \%$ of the analyzed streamflow gauges show an increase. The positive regional trend for the Atrato and San Juan flows coincide with areas of large increasing trends in precipitation.

Hurtado and Mesa (2015) developed a reanalysis of the precipitation field in Colombia, comprising 384 fields of monthly precipitation in the period 1975-2006 at a spatial resolution of 5 minutes of arc. For the reanalysis, they used records of 2270 rain gauges and various satellite-derived products for the most recent period. Then using Empirical Orthogonal Functions, Principal Component Analysis and statistical tests they looked for changes or trends. According to their results, both the Mann - Whitney mean change test and the simple $t$ trend test indicate increasing precipitation trends mainly in the Pacific, Orinoco, and Amazon basin regions. In most of the Andean region, there are no changes or trends.

Another line of work has been the use of global climate models (GCM): Pabón (2005); Ruiz (2007, 2010); IDEAM-Colombia (2010). These models adequately represent the core of the physical processes, although not the totality, particularly rainfall, tropical convection, and topography. Besides, spatial resolution is not generally adequate for regional studies. In general, there is the possibility of correcting these deficiencies through the use of mesoscale models that have finer spatial resolution and better represent convective processes. This methodology, known as downscaling, has advanced, but it is not free of difficulties.

Ruiz (2010) and Pabón (2005) analyze the results of the low-resolution global models to conclude that "annual precipitation would be reduced in some regions and would increase in others. In the regions where there is a certain degree of coincidence in most of the models and current trends about an increase are: the North and Central Pacific, Middle Magdalena, Sabana de Bogotá, Sogamoso River Basins, Catatumbo, 
112 Arauca, Piedemonte Llanero, Central Orinoquia, Central Amazon and Amazonian piedmont. In those

places the increase in rainfall compared with the typical period 1961-1990 could be between 10 and 15 $\%$ by 2050 and between 15 and $25 \%$ for the year 2080 . For the other regions, the study says that it is difficult to arrive at a concrete result since the different models present contradictory results". The results of the different IPCC models are available in http://www.climatewizard.org/. From there one can conclude that predicted change in rainfall for Colombia in scenario A1B for the average of the models indicate an increase of around ten \% for all of Colombia, except the northernmost zone. If the models or scenarios are examined individually the general trend is the same, although the magnitudes vary. In general, for most of Colombia, they predict positive trends, except for the most northern part where they predict a decreasing trend.

Pabón (2005); Ruiz (2007, 2010); IDEAM-Colombia (2010) went beyond low-resolution models into higher resolution using the regional model PRECIS (Providing Regional Climates for Impacts Studies) of the United Kingdom and the global model GSM-MRI (Global Spectral Model) of Japan. The results obtained can be summarized by quoting the Colombian 2nd Communication: "The areas that on average, by the end of the 21st century, would have the greatest reductions in precipitation would be the departments of Huila, Putumayo, Nariño, Cauca, Tolima, Córdoba, Bolivar and Risaralda where the rains would be reduced close to $15 \%$ with respect to the 1971-2000 climatology. Likewise, it is possible that rainfall increases near $10 \%$, in large areas of Chocó. From the point of view of the most pessimistic scenarios (A2, for example), the most significant reductions in rainfall throughout the 21 st century would occur in Córdoba, Cauca, Bolívar, Caldas, Sucre, Valle, Antioquia, Nariño and Risaralda, where it would rain between 70 and $80 \%$ of the rainfall recorded during the period 1971-2000 (that is, reductions between $20 \%$ and $30 \%)$."

However, some contradictions are striking. The minimum consistency required is that during the historical period the results of the models correspond to the observations. The trends in precipitation deduced from low-resolution global models do seem to be consistent with the trends observed in historical records. However, there is no consistency between the predictions of high-resolution models and low-resolution models. This single observation disqualifies their results of the high-resolution models.

Supported by these IDEAM results, UPME has analyzed the vulnerability of the Colombian electricity sector, which on average supplies 70\% through hydro-electricity (ACON-OPTIM, 2013). The monthly flows that feed each reservoir were projected using the decreasing trends of precipitation. As expected, they found a generalized decrease for the three climate change scenarios analyzed (A2, B2, and A1B). It is worth mentioning the analysis they make of these results: "Although the results obtained coincide with reductions in the water supply of the reservoirs, in many cases the percentage changes in the monthly flows are exaggerated, reaching reductions greater than $50 \%$ of the current condition. Those values are considered unlikely considering that the recorded flow series do not show sufficient statistical evidence to demonstrate that there is any linear decreasing trend". Such studies give rise to policies and actions that have clear, practical consequences.

Urán (2015) carried out an analysis of the scaling between precipitation and temperature limited by the Clausius-Clapeyron using 86 stations of precipitation and 9 temperature stations over the Antioquia region of Colombia, with 15 minutes resolution. He also used rain derived from TRMM data (Tropical Rainfall Measure Mission) with rainfall intensities every 3 hours. He found that for temporal scales greater than 12 hours the trends are no longer significant trends. For the finer temporal scales trends become significant for extreme deciles of the distribution. He reports a close scaling due to the Clausius-Clapeyron relation limiting the intensification of precipitation following the ideas of O'gorman and Schneider (2009). 


\section{STUDY AREA AND DATA} Soden and Held, 2006; Wentz et al., 2007). of wet days and an increase in dry spell length. stations.

In response to global warming, the hydrological cycle also changes. A warmer atmosphere means more radiative cooling of the troposphere, which is a growing function of temperature. The highest infra-red radiation emission corresponds to the balance required to compensate for the greater radiation absorbed. To the extent that changes in cloudiness or the absorption of radiation by water vapor offset the necessary radiative cooling, changes in precipitation may occur. Regionally, the winds determine where there is an increase or a decrease. If the winds change little, compared to the humidity they transport, the wet regions import more water, and there could be more rain, while the dry ones could be drier (Mitchell et al., 1987;

Giorgi et al. (2011) introduce a new measure of hydroclimatic intensity (HY-INT), which integrates metrics of precipitation intensity and dry spell length. The responses of these two metrics to global warming are deeply interconnected. They found clear increasing trends of HY-INT in global and regional climate models. Depending on the region, the increase in HY-INT is due to an increase in precipitation intensity, dry spell length, or both. They also examined late twentieth-century observations and concluded that they also exhibit dominant positive HY-INT trends, providing a hydroclimatic signature of late-twentiethcentury warming. Precipitation intensity increases because of increased atmospheric water holding capacity. However, increases in mean precipitation need increases in surface evaporation rates, which are lower than for atmospheric moisture. Global warming increase potential evapotranspiration which may probably result in an increase in actual evaporation, or evapotranspiration in plants, only if adequate moisture is available. So potentially there is more drying, but in drought situations part of any extra energy goes into raising temperatures, thereby amplifying warming over dry land. This feedback leads to a reduction in the number

We analyzed data from 1706 sites in the whole territory of Colombia, 1062 in the Andes region. The other sites are in the Amazon (77), the Caribbean 398, the Orinoco (91) and the Pacific (78) regions. Data comprise daily time series of rainfall amount. Since the method requires no missing data (Section 4) we trim the series to the common period between 1970 and 2014. We also fill the missing data with data from the CHIRPS (Funk et al., 2015) data-set. A condition for this filling was that the percentage of missing days did not exceed $30 \%$. Otherwise, the whole year is missing. The authors tested the performance of CHIRPS in Colombia in previous studies (Urrea et al., 2019; Urrea, 2017; Urrea et al., 2016). Of the original IDEAM dataset, we dropped for our analysis all the stations with more than $50 \%$ missing data in the common period and others that do not pass a minimum quality check. The final data-set has 1629

Figure 1 shows the IDEAM the rain gauge network. The network covers a range of elevations from sea level in the Caribbean and Pacific coasts to 4150 meters above sea level in the Andes. Notice also the low density of the gauge network in the Amazon and Orinoco regions.

Colombian climate is tropical, mean annual temperature is high, above $25^{\circ} \mathrm{C}$ at sea level, the diurnal range of temperature exceeds the annual range, and the annual range is minimal, less than $5^{\circ} \mathrm{C}$ (Snow, 1976). Precipitation is abundant in comparison with any other place in the world. There are places of the Pacific coast with perennial rain with mean annual totaling $12200 \mathrm{~mm}$. Over the Orinoco and Amazon basins in Colombia, the mean annual precipitation varies from 2000 to $7000 \mathrm{~mm}$ per year. In the Caribbean coast the average is of the order of $1500 \mathrm{~mm}$, but to the north, there are places with near $300 \mathrm{~mm} / \mathrm{year}$. In the Andean region mean annual precipitation ranges from 1000 to $3000 \mathrm{~mm} /$ year. 


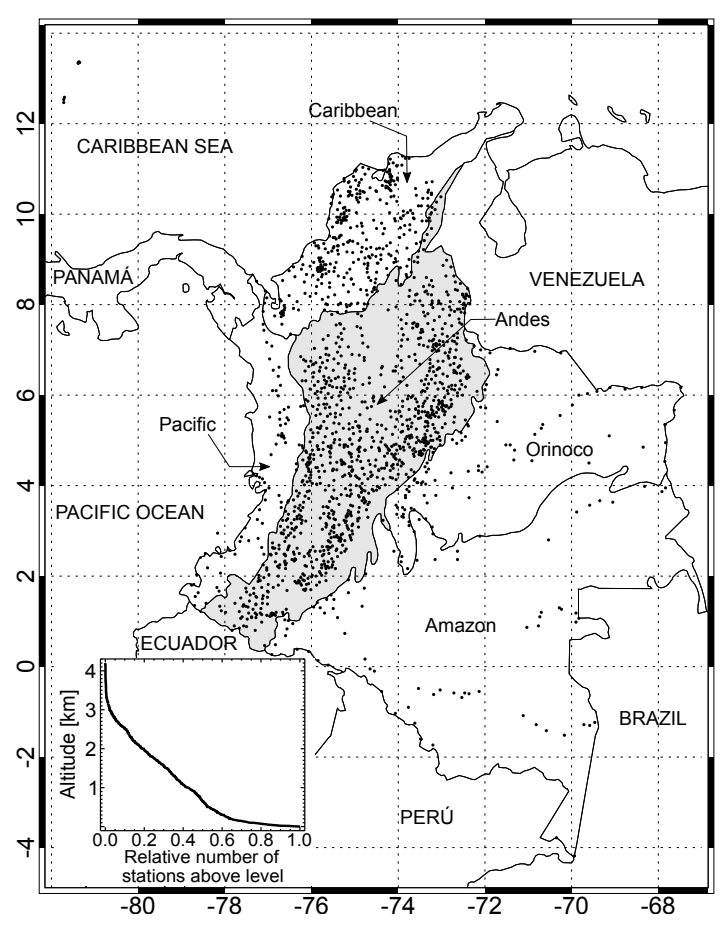

Figure 1. Location of the IDEAM rain gauge network that was used in this work. The bottom left graph shows the vertical distribution of the rain stations. The map also shows the five natural regions of Colombia (IGAC, 1997).

Atmospheric moisture is transported toward Colombia by the trade winds from the Caribbean sea, the Atlantic ocean through both Amazon and Orinoco basins that themselves contribute with recirculating moisture. Also from the Pacific ocean, westerly winds contribute to the massive convergence of moisture over Colombia. The migration of the inter-tropical convergence zone and three low-level jet streams (Chocó,

201 Caribbean, and South America) are part of the complex circulation given rise to that high precipitation 202 (Poveda et al., 2014).

\section{METHODS}

203 Hydroclimatic intensity (Giorgi et al., 2011) is evaluated using the HY-INT indicator

$$
\mathrm{HY}-\mathrm{INT}=\mathrm{INT} \times \mathrm{DSL},
$$

204 where INT and DSL are mean intensity during wet days and mean dry spell duration for each year in the 205 record. In both cases, one works with scaled variables using the respective inter-annual mean as scale factor 206 (Giorgi et al., 2011). Therefore the long-term average of both INT and DSL are 1.

207 We also evaluate the trends of $\mathrm{P}$, the total annual precipitation for each year; and LW, the average length 208 of a wet spell in each year. We also counted the number of wet and dry days in each year as well as the 209 number of dry and wet spells in each year.

210 Also, we constructed an extreme indicator of the hydrologic cycle generalizing (Giorgi et al., 2011) ideas. 211 For that, we computed the maximum daily intensity for each year (INTX) and the maximum dry spell 212 length for each year (DSLX). In other words, for this proposal instead for the average of the corresponding 
213 variable for each year, we take the maximum. Their product gives the HY-INTX indicator of the strength of 214 the hydrologic cycle.

215 For each year in the record we computed each one of the variables mentioned above. Therefore for each 216 gauge and each variable, we have a time series. We then proceed to evaluate the existence of trends in those 217 time series for each gauge.

\subsection{Trend analysis}

219 We use the Mann-Kendall test (Mann, 1945; Kendall, 1955) for autocorrelated data (Hamed and 220 Ramachandra-Rao, 1998) to evaluate the existence of trends in the time series, and the Sen's slope 221 estimator (Sen, 1968) for calculating the magnitude of the trend. A summary of these techniques follows. 222 More details in the cited references.

The null hypothesis of the Mann-Kendall test is that the data come from independent and identically distributed random variables (iid) and hence no long-term trend exists. When the data are iid, the statistic $S$,

$$
S=\sum_{i=1}^{n-1} \sum_{j=i+1}^{n} \operatorname{sgn}\left(x_{j}-x_{i}\right)
$$

has asymptotic normality with mean zero and variance $\operatorname{Var}[S]$

$$
\operatorname{Var}[S]=\frac{n(n-1)(2 n+5)}{18}-\frac{1}{18} \sum_{j=1}^{m} t_{j}\left(t_{j}-1\right)\left(2 t_{j}+5\right) .
$$

In Eq. $2 n$ is the sample size, $x_{t}$ is the value of the time series at time $t$, and $\operatorname{sgn}\left(x_{j}-x_{i}\right)$ is defined by

$$
\operatorname{sgn}\left(x_{j}-x_{i}\right)=\left\{\begin{array}{rll}
1 & \text { if } & x_{j}-x_{i}>0 \\
0 & \text { if } & x_{j}-x_{i}=0 \\
-1 & \text { if } & x_{j}-x_{i}<0
\end{array}\right.
$$

The sum in the last term of Eq. 3 accounts for the reduction in variance due to the existence of tied ranks (Hamed, 2008). In Eq. $3 \mathrm{~m}$ is the number of groups of tied ranks and $t_{j}$ is the number of ranks in group $j$.

The standardized test statistic $Z$ is calculated by

$$
Z= \begin{cases}\frac{S-1}{\sqrt{\operatorname{Var}[S]}} & \text { if } S>0 \\ 0 & \text { if } S=0 \\ \frac{S+1}{\sqrt{\operatorname{Var}[S]}} & \text { if } S<0\end{cases}
$$

231 The null hypothesis of no trend is rejected if $|Z|$ exceeds the value $\left|Z_{1-\alpha / 2}\right|$ of the standard normal distribution for a given significance level $\alpha$.

The result of Mann-Kendall test is sensitive to autocorrelation in the data. Positive autocorrelation increases the probability of rejecting the null hypothesis when it is true, and negative autocorrelation increases the probability of not rejecting the null hypothesis when it is false. This effect occurs because of a bias in the estimation of $\operatorname{Var}[S]$. Hamed and Ramachandra-Rao (1998) suggested the empirical formula 
237 in Eq. 6 for calculating $\operatorname{Var}[S]$ in the presence of autocorrelation.

$$
\operatorname{Var}\left[S_{a c}\right]=\operatorname{Var}[S] \times\left[1+\frac{2}{n(n-1)(n-2)} \sum_{i=1}^{n-1}(n-i)(n-i-1)(n-i-2) \rho_{s}(i)\right]
$$

238 where $\rho_{s}(i)$ is the auto-correlation function of the ranks of the observations.

239

240

241

242

The Sen's non-parametric method (Sen, 1968) estimates the long-term linear trend slope of a time series as the median value of the slopes between all pairs of points in the series. For $N=n \cdot(n-1) / 2$ pairs of data in the series, the $N$ slopes, $Q$, are calculated as shown in Eq. 7. The median of $Q$ is the Sen's slope estimator.

$$
Q_{i}=\frac{x_{j}-x_{k}}{j-k}, \quad i=1,2, \ldots N ; \quad 1 \leq j \leq n-1 ; \quad j \leq k \leq n .
$$

$$
\frac{d \mathrm{HY}-\mathrm{INT}}{d t}=\mathrm{INT} \frac{d \mathrm{DSL}}{d t}+\mathrm{DSL} \frac{d \mathrm{INT}}{d t}
$$

And because all the variables are scaled, what one needs is the logarithmic derivative

$$
\frac{1}{\mathrm{HY}-\mathrm{INT}} \frac{d \mathrm{HY}-\mathrm{INT}}{d t}=\frac{1}{\mathrm{DSL}} \frac{d \mathrm{DSL}}{d t}+\frac{1}{\mathrm{INT}} \frac{d \mathrm{INT}}{d t} .
$$

Therefore the temporal trend slopes satisfy

$$
m_{H Y-I N T}=m_{I N T}+m_{D S L}
$$

\section{RESULTS}

Neglecting data autocorrelation in trend analysis increases the probability of error in the Mann-Kendall test result (Kulkarni and von Storch, 1992; von Storch, 1995). We compared the results of the classic MK test and the MK test for autocorrelated data proposed by Hamed and Ramachandra-Rao (1998) in our 1629 series data set, and conclude that ignoring the auto-correlation may lead to false trends of the order of $20 \%$ of the gauges, and false no trends in of the order of $10 \%$ of the gauges.

Table 1 presents in each row the four elements of the confusion matrix for the Mann-Kendall test that does not take into account auto-correlation in comparison with the one that does. We take this last one as the correct method for the comparison. The most significant error (from 18 to 25\%) comes from false trends. However, there are also errors due to false no trends (from 11 to 15\%). As a result, the accuracy (total number of hits) is between 60 and $71 \%$. It is always recommended to take into account the auto-correlation of the series to evaluate the significance of trends.

We also considered the possible implication of the definition of the year. Besides the calendar year, we considered a hydrology year starting on April 1st. The idea was that the end of the calendar year might 
Table 1. Confusion matrices for the evaluation method of the significance of the trends for each of the indicated variables without taking into account auto-correlation. For the purpose of the illustration the Mann-Kendall test with auto-correlation is considered the true one.

\begin{tabular}{lrrcr}
\hline Variable & $\begin{array}{c}\text { true trend } \\
\text { R-R }\end{array}$ & $\begin{array}{c}\text { false trend } \\
\text { R-NR }\end{array}$ & $\begin{array}{c}\text { false no trend } \\
\text { NR-R }\end{array}$ & $\begin{array}{r}\text { true no trend } \\
\text { NR-NR }\end{array}$ \\
\hline \multicolumn{5}{c}{ Number of gauges (Percentage of the total number of gauges) } \\
\hline P & $45(3 \%)$ & $293(18 \%)$ & $180(11 \%)$ & $1111(68 \%)$ \\
INT & $116(7 \%)$ & $400(25 \%)$ & $245(15 \%)$ & $868(53 \%)$ \\
DSL & $62(4 \%)$ & $316(19 \%)$ & $184(11 \%)$ & $1067(66 \%)$ \\
HY-INT & $108(7 \%)$ & $393(24 \%)$ & $212(13 \%)$ & $916(56 \%)$ \\
\hline
\end{tabular}
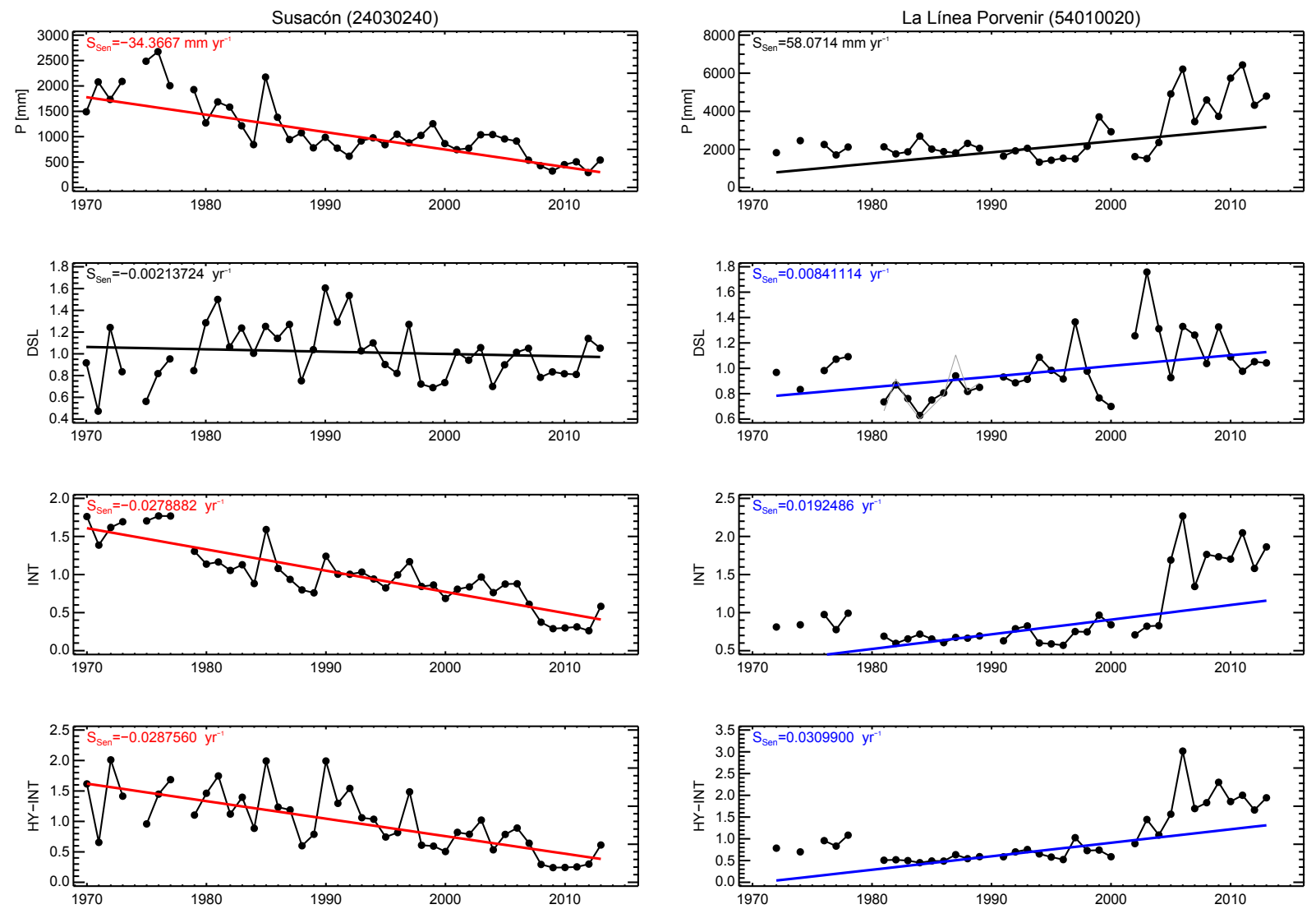

Figure 2. Two examples of trend analysis for (top to bottom) P, DSL, INT and HY-INT for two representative stations. Left: Susacón in Boyacá, at 2550 masl. Right: La Línea El Porvenir in Risaralda, at 1955 masl.

split the longest dry spell. Because the dry season usually starts in mid-December and ends in March in Colombia. However, as we show below, the dominant fact for the significant trends is an increase in the number of wet days $(70 \%)$, not the length of the dry season.

Figure 2 illustrates two of the 1629 cases of the trend analysis. Notice the treatment of the missing years that may come for any missing day. For the Susacón gauge in the left part of the Figure, the trends in P, INT, and HY-INT are decreasing and statistically significant. However, the trend in DSL is not. For La Línea El Porvenir station in the right side of the Figure DSL, INT, and HY-INT have significant positive trends, whereas $\mathrm{P}$ has an increasing non statistically significant trend. 

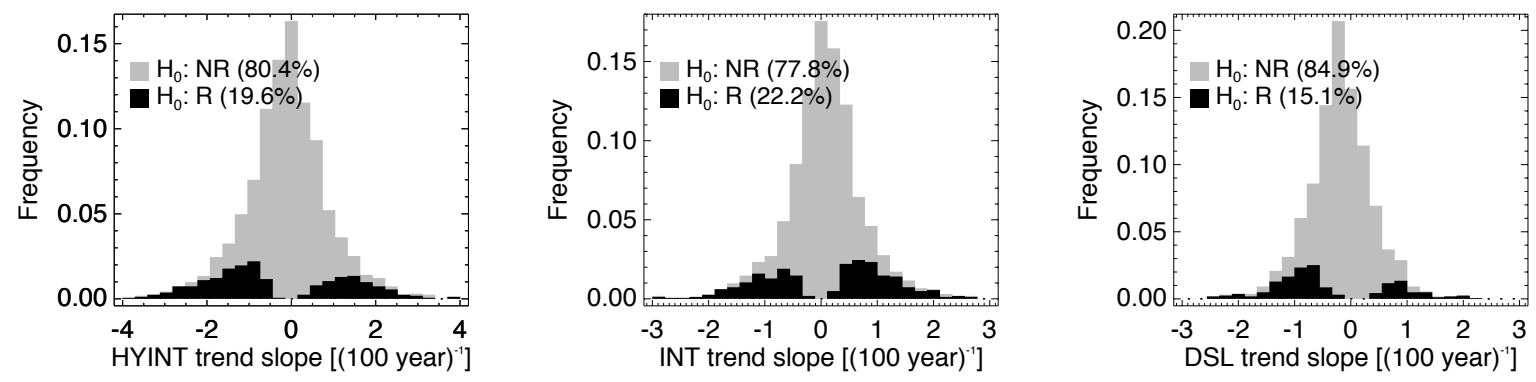

Figure 3. Histograms of the HYINT (left), INT (center) and DSL (right) trend slopes of the 1629 rain gauges used. Non significant trends $\left(\mathrm{H}_{0}\right.$ : Stationary hypothesis not rejected, $\left.\mathrm{NR}\right)$ in grey and significant trends in black $\left(\mathrm{H}_{0}\right.$ : Stationary hypothesis rejected, $\left.\mathrm{R}\right)$.
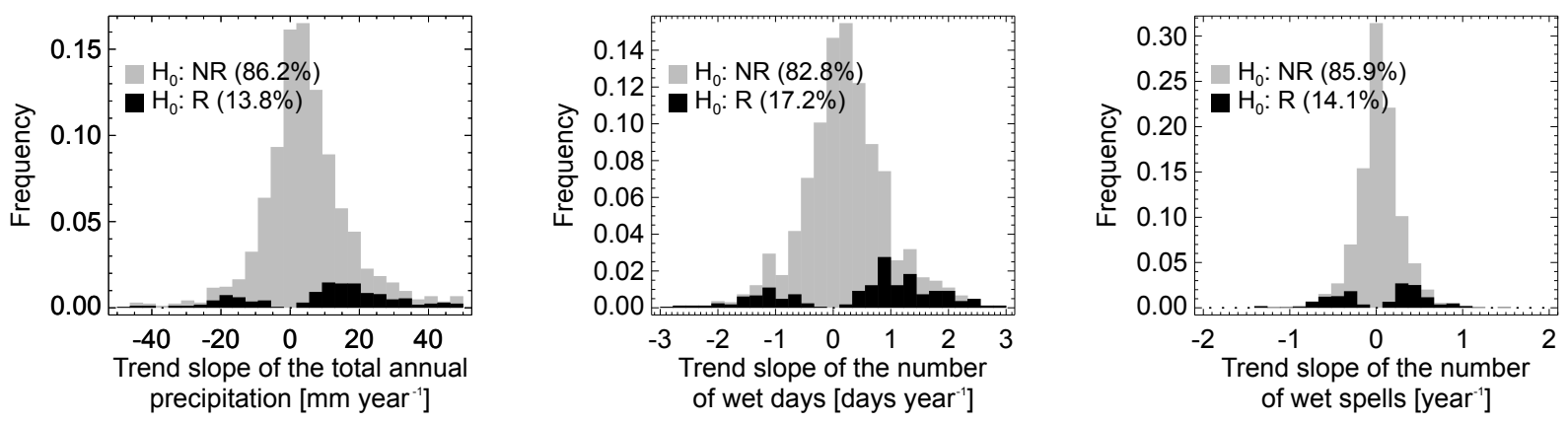

Figure 4. Same as Figure 3 for the trend slope of the total annual precipitation (left), the number of wet days in the year(center) and number of wet spells in the year(right).

Table 2 summarizes the results of the trend analysis for the 1629 stations and the more relevant variables. The first observation is that only a minority of the stations show significant trends. Among the variables, INT shows the largest percentage of significant trends, but only reaching a $22.2 \%$ of the stations. The least percentage is for the variable DSLX with only 9.3\%. A second observation is that the extreme variables do not show a larger percentage of significant trends in comparison with the corresponding average variables: For INTX the percentage is 9.3 in comparison with 22.2 for INT. Similarly, for DSLX is 9.3 in comparison with 15.1 for DSL; and for HYINTX is 9.4, whereas for HY-INT it is 19.6. Among the stations with statistically significant trends, the analysis of positive and negative trends is interesting. There is a clear majority among the significant ones for positive trends for $\mathrm{P}$, the number of wet days, LW, Number of both dry and wet runs, INTX, and INT. Similarly, there is a majority of a significant negative trend for DSLX, HYINTX, number of dry days, DSL, and HY-INT.

Only $40 \%$ of the significant HY-INT stations have a positive trend, even though one of its factors, INT, has a majority of positive trends (57\%) among the significant ones. However, that percentage reduces to $43 \%$ among the ones with significant HY-INT trend. The other reason is the sign of the trends in DSL, $69.1 \%$ negative among significant DSL trends. This percentage only is reduced to $61 \%$ when one considers stations with significant HY-INT trend. Besides, the histograms of the slopes of the trends in Figure 3 illustrate well this point. Therefore for Colombia's humid climate HY-INT, the indicator proposed by Giorgi et al. (2011) to measure the strength of the hydrologic cycle, only makes sense partially concerning INT, but not for dry spells. Because, they are not increasing in length significantly, not even among the small number of stations with significant trends that on the contrary are getting shorter for the average dry run and more so for the extreme ones. 

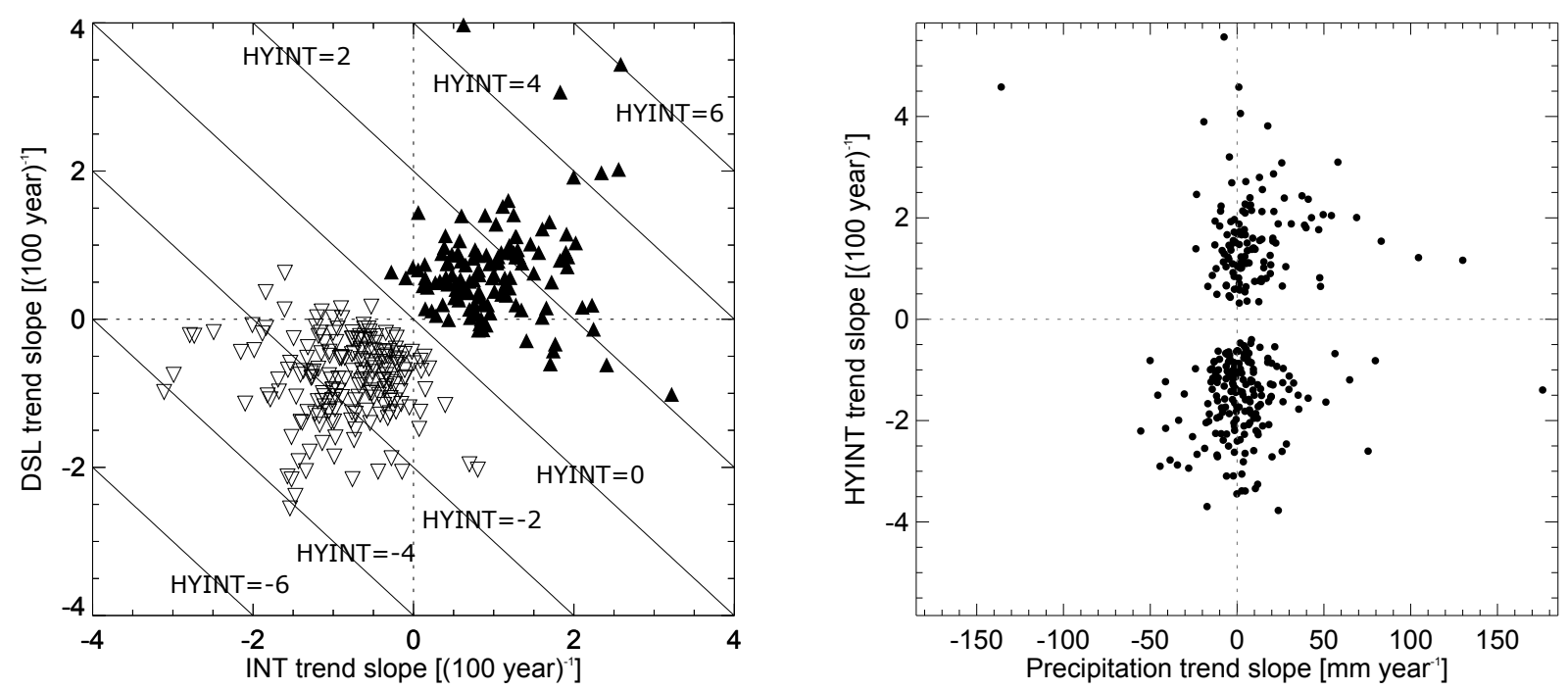

Figure 5. Left: Dispersion diagram of the DSL trend slope vs. INT trend slope for all stations with significant HY-INT trend slope. Notice that because of Eq 10 the trend slope of HY-INT is the sum of the trend slopes of INT and DSL. This equation explains the slanted iso-lines for the HY-INT trend slope. Right: Dispersion diagram of the HY-INT trend slope vs. precipitation trend slope for all stations with significant HY-INT trend slope
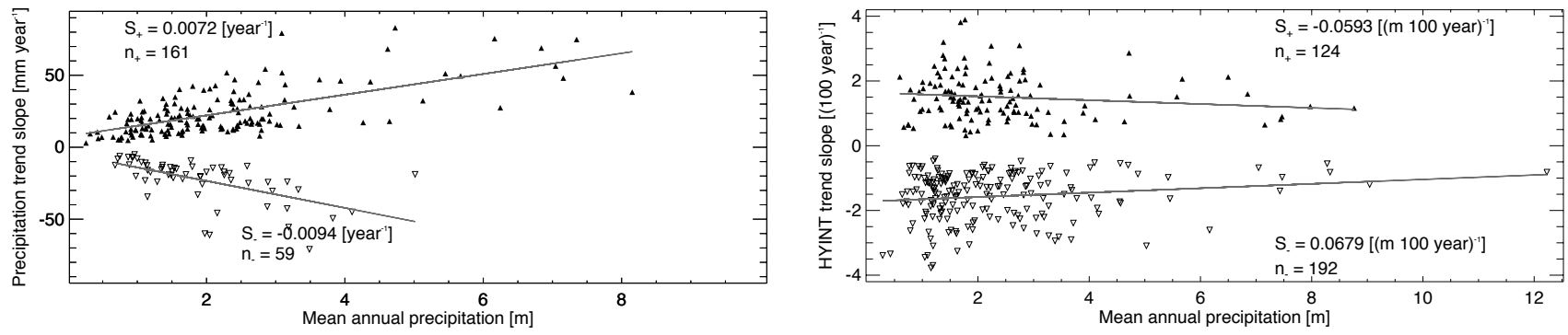

Figure 6. Precipitation trend slope vs. mean annual precipitation (A) and HY-INT trend slope vs. mean annual precipitation (B) for the stations with significant trend. $n_{+}$and $n_{-}$are number of stations with positive (negative) slope. $S_{+}$and $S_{-}$are the corresponding slopes.

Figure 4 shows the histograms of the trend slopes for P, the number of wet days and the number of wet spells. Again, the majority of the stations do not have significant trends. However, among the significant ones, there is a clear majority of positive trends.

Figure 5 allows further analysis of the result about HY-INT discussed above. Notice that almost all stations with positive trend slope for HY-INT have positive trend slopes for both INT and DSL. Conversely, almost all with negative trends for HY-INT have negative trends for INT and DSL. Therefore, most of the points in the figure are in either the first or the third quadrant (89\%). Of the 320 stations with a significant trend in HT-INT, 124 and 170 do not have significant trends for INT and DSL respectively.

Figure 5 also shows the relation between the trend slopes for P and HY-INT. There are two groups of stations also, depending on the sign of the HY-INT trend. However, among both, there are positive and negative trends in $\mathrm{P}$.

For the significant trends, the magnitude of the trends seems to be related linearly with $\mathrm{P}$, see Figures $6 \mathrm{~A}$ and $6 \mathrm{~B}$. This tendency is more clear for the $\mathrm{P}$ trend than for the HY-INT trend. The magnitude of the $\mathrm{P}$ 
Table 2. Basic statistical analysis of the significant trends of the different variables using the calendar year and taking into account autocorrelation: P: Total Annual Precipitation, INT: averaged scaled intensity on wet days, DSL: averaged scaled dry run length; HYINT=INT $\times$ DSL; N stands for number; LW: averaged scaled length of wet runs. In addition extreme variables are computed for the hydrologic year (April 1st to March 31): INTX: the maximum daily intensity; DSLX: the maximum dry run length; HY-INTX=INTX $\times$ DSLX; and LWX: The maximum wet run length. Column symbols: $N$ Rej is the number of stations for which the null hypothesis of no trend was rejected; \% Rej/T is the percentage of total stations that rejected the test; N Positive is the number of stations with significant positive trend; and finally \% Pos/Rej is the percentage of those with positive trend among the ones with significant trend.

\begin{tabular}{lrrrr}
\hline Variable & NRej & $\%$ Rej/T & N Positive & $\%$ Pos/Rej \\
\hline P & 225 & 13.8 & 165 & 73.3 \\
INT & 361 & 22.2 & 206 & 57.1 \\
DSL & 246 & 15.1 & 76 & 30.9 \\
HY-INT & 320 & 19.6 & 128 & 40.0 \\
N Wet Days & 281 & 17.2 & 200 & 71.2 \\
N Dry Days & 282 & 17.3 & 80 & 28.4 \\
LW & 286 & 17.6 & 183 & 64.0 \\
N Wet Runs & 229 & 14.1 & 134 & 58.5 \\
N Dry Runs & 235 & 14.4 & 144 & 61.3 \\
INTX & 148 & 9.3 & 85 & 57.4 \\
DSLX & 148 & 9.3 & 29 & 19.6 \\
HYINTX & 149 & 9.4 & 39 & 26.2 \\
LWX & 228 & 14.4 & 146 & 64.0 \\
\hline
\end{tabular}

trend slope increases with precipitation irrespective of the sign. Whereas for the HY-INT case, positive trend slope decreases with $\mathrm{P}$ and the negative slope increases.

As expected from the small number of stations with significant trends, the space distribution does not seem to show any pattern. Maps in figure 7 show in the location of each station the sign of the trend in HY-INT, INT, DSL, and P. Nevertheless, Table 3 shows that though the percentage of stations with a significant trend is small, there is a majority of positive trends for total annual precipitation overall (73\%) and an overwhelming majority in the Pacific (94\%) and Caribbean (91\%) regions. These results accord with previous studies for the Pacific region. For the Caribbean region, the results show a trend in the opposite direction to the predictions of GCM's (see section 2).

Bearing in mind that only a fraction (10 to $20 \%$ ) of the stations show statistically significant trends, among the significant ones the Pacific region exhibits differences with the overall behavior. For the HY-INT variable, the percentage of significant trends is $32 \%$ whereas overall is only $20 \%$ and the percentage of increasing trends goes from $40 \%$ (overall) to $50 \%$. For the INT variable, the corresponding figures go from $57 \%$ to $74 \%$. Similarly, for the number of wet spells, the percentage of increasing trends among the significant ones goes from $59 \%$ overall to $67 \%$ for the Pacific region. For the number of wet days in the year, the percentage of significant trends is $27 \%$ whereas overall is only $17 \%$. Moreover, for DSLX the significant negative trends go from $80 \%$ to $93 \%$. Together with the observation about total annual precipitation, these changes indicate that the region tends to a more humid condition.

For the rest of the regions, the significant trends in HY-INT are not notably different from the total. Except for the Orinoco region that we analyze below.

Besides the changes in $\mathrm{P}$ mentioned above, for the Caribbean region, the percentage of increasing trends among the significant trends differs from the overall in the number of wet spells (59\% overall vs. $76 \%$ ) and 
(A) HYINT trend sign
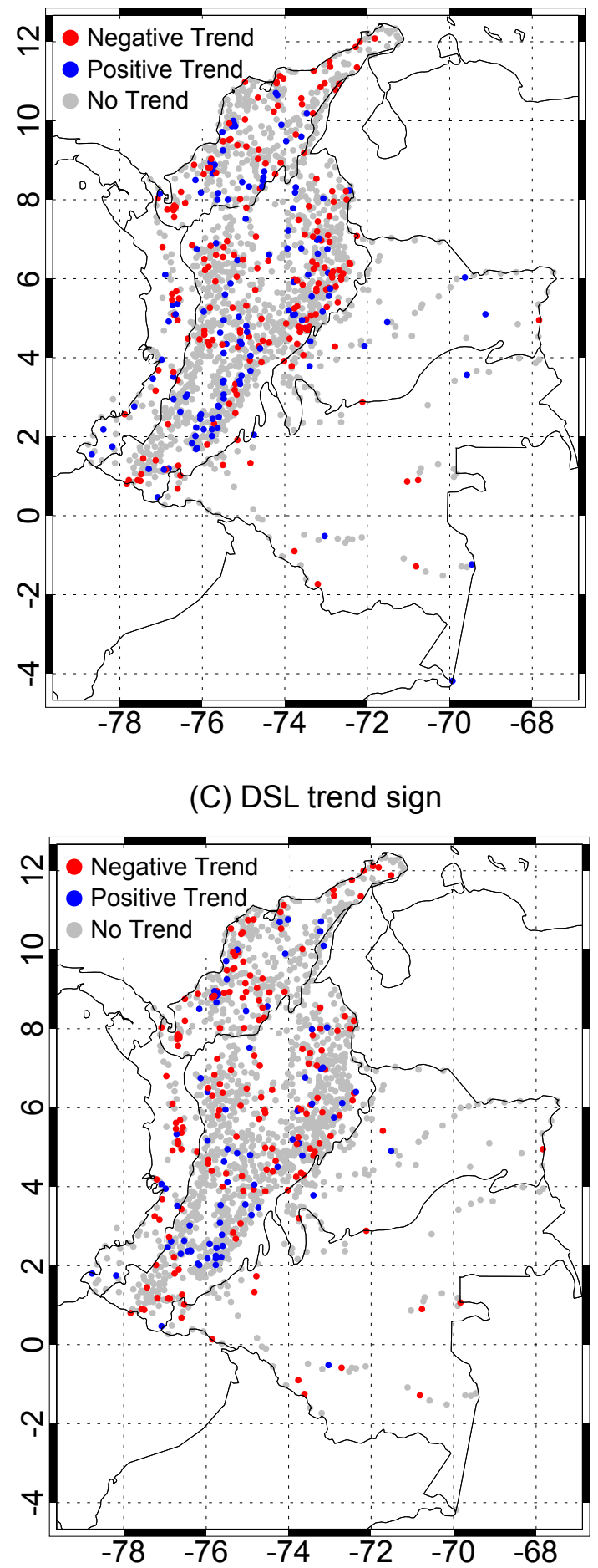

(B) INT trend sign

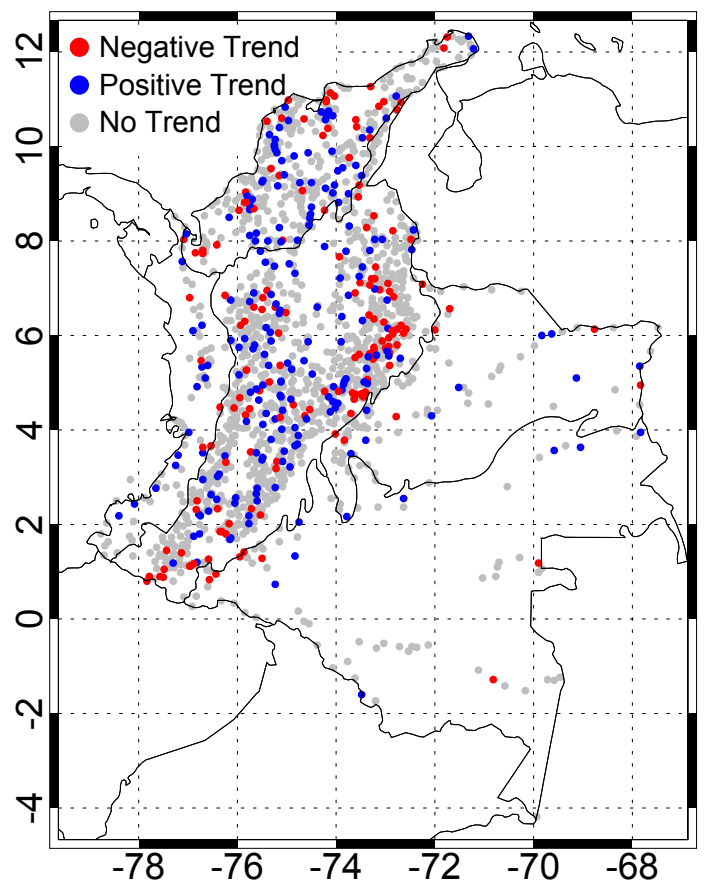

(D) Precipitation trend sign

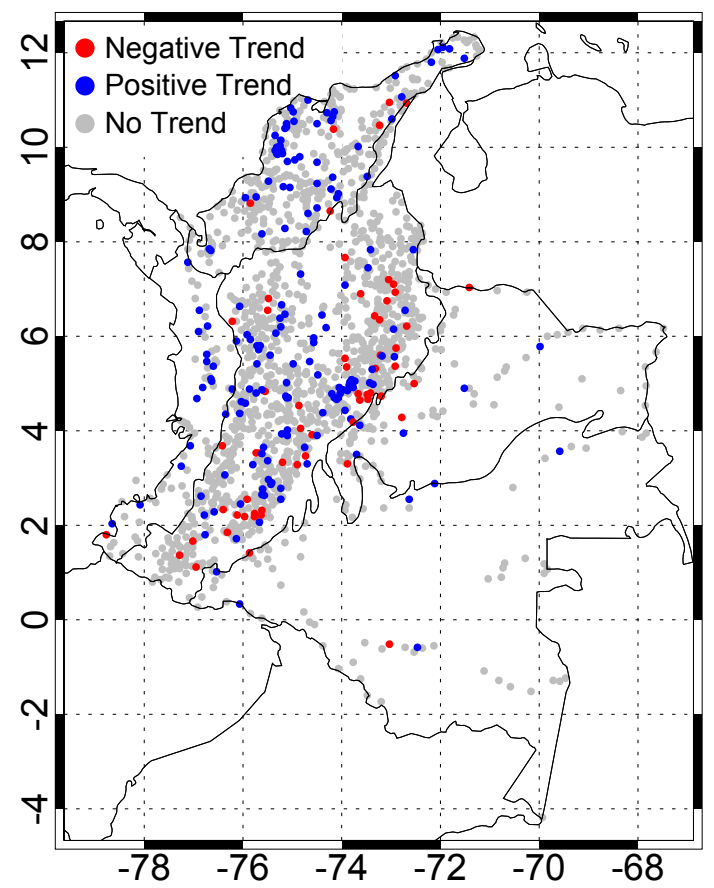

Figure 7. Maps of the trend sign for HY-INT (A) and INT (B), DSL (C) and P (D). Significant positive (increasing) trends in blue, negative (decreasing) trends in red and no significant trends in gray.

the INT variable (57\% overall vs. $63 \%$ ). With the caveat of the low number of stations with statistically significant trends, these results also point in the direction of a wetter region. 
Table 3. Regional summary of the trends of rain gauges for Total Annual Precipitation and HY-INT. Column symbols as in Table 2

\begin{tabular}{lrrrr}
\hline Region & N Rej & \% Rej/T & N Positive & $\%$ Pos/Rej \\
\hline \multicolumn{5}{c}{ Total Annual Precipitation } \\
\hline Amazon & 8 & 11 & 6 & 75 \\
Andes & 133 & 13 & 85 & 64 \\
Caribbean & 57 & 15 & 52 & 91 \\
Orinoco & 9 & 10 & 5 & 56 \\
Pacific & 18 & 24 & 17 & 94 \\
Total & 225 & 14 & 165 & 73 \\
\hline \multicolumn{5}{c}{ HY-INT } \\
\hline Amazon & 16 & 21 & 5 & 31 \\
Andes & 188 & 19 & 74 & 39 \\
Caribbean & 81 & 21 & 31 & 38 \\
Orinoco & 11 & 13 & 6 & 55 \\
Pacific & 24 & 32 & 12 & 50 \\
Total & 320 & 20 & 128 & 40 \\
\hline
\end{tabular}

\section{DISCUSSION}

349 Our results about the trends in annual precipitation agree in some way with the previous studies reported

For the Amazon region, the variables with different behavior than the overall are in the decreasing trends of DSL (69\% overall vs. 92\%) and DSLX (80\% overall vs. 94\%). That means that the lengths of dry spells are getting shorter.

The Orinoco region has few stations and much fewer significant trends. Among those the variables HY-INT, number of wet days, and the number of wet spells show notorious differences in the percentage of increasing trends with the countrywide numbers: 40 vs. $55 \%, 71$ vs. $47 \%$, and 59 vs. $64 \%$ respectively (Off each pair the first figure is for the whole country and the second one is for the region).

The Andes region has a substantial number of all the stations in the country, and therefore for all the variables, the behavior of each trend is close to the one of the whole country, except for the number of wet spells. For that variable, the percentage of positive trends among the significant ones is only $46 \%$ whereas the country average is $59 \%$. This reduction is possible because for the other four regions the percentage increases.

Figure 8 shows the distribution of the record length of all the stations coding with gray the ones corresponding to a significant trend in HY-INT. The percentage of stations with significant trend out of the total number of stations in each record length bin does not change significantly except at the tails. In other words, the probability that the HY-INT trend of a given station is statistically significant is pretty much uniform as a function of the record length. This observation indicates that for the set of rain gauges analyzed the record length does not explain the lack of significant trends. On the contrary, the reason for the limited number of significant stations with significant trend needs other explanation.

We also looked into the possible dependence of trend slopes on latitude, longitude, elevation, and seasonality of the annual regime of precipitation. However, there were not any pattern worth mentioning. in Section 2 that considered rain gauges: Increasing trends prevail over decreasing trends among the 
Record length histogram

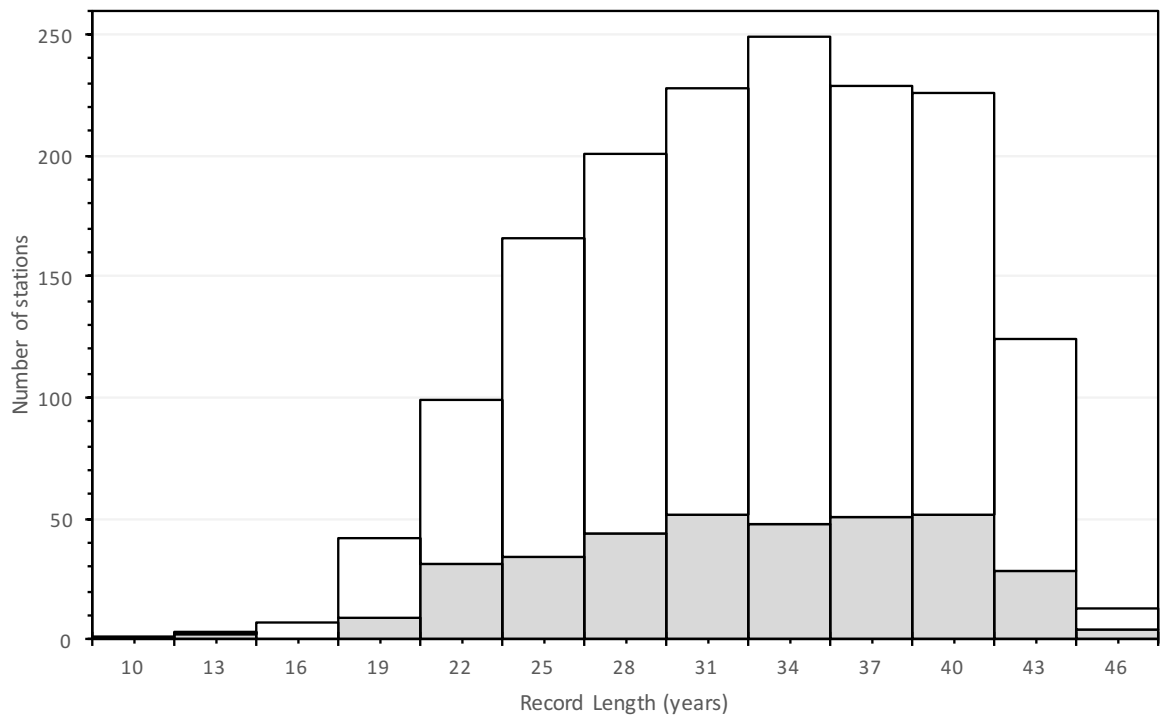

Figure 8. Histogram of the the record length (number of complete years) of the 1629 rain gauges used in this study. Stations with significant trend for HY-INT in gray. 
elucidate the effects of climate change over Colombian precipitation. In that sense, our results seem to suggest that ENSO is not becoming more intense or frequent. Also, the fact that majority of significant trends for total annual precipitation is positive for the Pacific region accords with the nonlinear ENSO warming suppression and a possible strengthening of the Chocó jet.

Other result is about the HY-INT index of Giorgi et al. (2011) to quantify the intensity of the hydrologic cycle. For many parts of the globe, it may be true that rainfall intensity and dry spell length are deeply interconnected. However, our results suggest that it is not the case for a humid tropical climate like Colombia's. At least for the few gauges with significant trends the two factors in the definition of HY-INT, rainfall intensity and dry spell length do not necessarily go together. For instance, of the $57 \%$ (205 out of 361) of the station with significant INT trend have a positive trend; but of those, $45 \%$ have positive DSL trend and 55\% negative one (92 and 113 respectively).

We wanted to complement HY-INT, the indicator of the intensity of the hydrologic cycle, by defining an extreme version, HYINTX, the product of the maximum daily rainfall times the maximum dry spell length. For Colombia, this indicator did not give any good results. Even they were weaker than the original HY-INT indicator. One reason for this failure seems to be that dry spell length tends to decrease even though the trend in maximum intensity is positive.

\section{ACKNOWLEDGMENTS}

We acknowledge Colombian meteorological service, IDEAM, for providing the rainfall data.

\section{REFERENCES}

ACON-OPTIM (2013). Estudio para determinar la vulnerabilidad y las opciones de adaptación del sector energético Colombiano frente al cambio climático. Informe final. Tech. rep., Unidad de Planeación Minero Energética, UPME-0223-290-dic/2013-V1. 416 págs., Bogotá

Cantor, D. (2011). Evaluación y análisis espaciotemporal de tendencias de largo plazo en la hidroclimatología colombiana. Master Thesis in Water Resources Engineering. Master Thesis in Water Resources Engineering, Universidad Nacional de Colombia, Medellín

Cantor, D. and Ochoa, A. (2011). Señales de cambio climático en series de lluvia en Antioquia. In IX Congreso Colombiano de Meteorología (Bogotá: IDEAM - Universidad Nacional de Colombia), 11 p. doi:10.13140/RG.2.1.1573.0326

Carmona, A. M. and Poveda, G. (2014). Detection of long-term trends in monthly hydro-climatic series of Colombia through Empirical Mode Decomposition. Climatic Change 123, 301-313. doi:10.1007/ s10584-013-1046-3

Eslava, J. A. (1993). Climatología y diversidad climática de Colombia. Revista de la Academia Colombiana de Ciencias Exactas, Físicas y Naturales 18, 507-538

Funk, C., Peterson, P., Landsfeld, M., Pedreros, D., Verdin, J., Shukla, S., et al. (2015). The climate hazards infrared precipitation with stations-a new environmental record for monitoring extremes. Scientific Data 2. doi:10.1038/sdata.2015.66

Giorgi, F., Im, E.-S., Coppola, E., Diffenbaugh, N. S., Gao, X. J., Mariotti, L., et al. (2011). Higher Hydroclimatic Intensity with Global Warming. Journal of Climate 24, 5309-5324. doi:10.1175/ 2011JCLI3979.1

Hamed, K. H. (2008). Trend detection in hydrologic data: The Mann-Kendall trend test under the scaling hypothesis. Journal of Hydrology 349, 350-363. doi:10.1016/j.jhydrol.2007.11.009 
Hamed, K. H. and Ramachandra-Rao, A. (1998). A modified Mann-Kendall trend test for autocorrelated data. Journal of Hydrology 204, 182-196. doi:10.1016/S0022-1694(97)00125-X

Hurtado, A. F. and Mesa, O. J. (2015). Cambio climático y variabilidad espacio-temporal de la precipitación en colombia. Revista EIA 12, 131-150

IDEAM-Colombia (2010). 2 a Comunicación Nacional ante la Convención Marco de las Naciones Unidas sobre cambio climático (Bogotá)

IGAC (1997). Mapa de Regiones Naturales de Colombia (Bogotá, Colombia: Instituto Geográfico Agustín Codazzi)

Kendall, M. G. (1955). Rank Correlation Methods (London, UK: Griffin), 2 edn.

Kohyama, T. and Hartmann, D. L. (2017). Nonlinear enso warming suppression (news). Journal of Climate 30, 4227-4251

Kulkarni, A. and von Storch, H. (1992). Monte Carlo experiments on the effect of serial correlation on the Mann-Kendall test of trend. Meteorologische Zeitschrift 4, 82-85. doi:10.1127/metz/4/1992/82

Macías, A. M. and Andrade, J. (2014). Estudio de generación eléctrica bajo escenario de cambio climático. Tech. rep., Unidad de Planeación Minero Energética, UPME, Bogotá

Mann, H. B. (1945). Nonparametric Tests Against Trend. Econometrica 13, 245-259. doi: 0012-9682(194507)13:3〈245:NTAT $\rangle 2.0 . C O ; 2-U$

Mayorga, R., Hurtado, G., and Benavides, H. (2011). Evidencias de cambio climático en Colombia con base en información estadística. Tech. rep., IDEAM-METEO/001-2011 Nota técnica del IDEAM

Mejía, J. F., Mesa, O. J., Poveda, G., Vélez, J. I., Hoyos, C. D., Mantilla, R. I., et al. (1999). Distribución espacial y ciclos anual y semianual de la precipitación en Colombia. Dyna 127, 7-26

Mesa, O., Poveda, G., and Carvajal, L. F. (1997). Introducción al Clima de Colombia (Santa Fe de Bogotá, D.C., Colombia: Universidad Nacional de Colombia)

Mitchell, J. F., Wilson, C., and Cunnington, W. (1987). On co2 climate sensitivity and model dependence of results. Quarterly Journal of the Royal Meteorological Society 113, 293-322

Ochoa, A. and Poveda, G. (2008). Distribución espacial de señales de cambio climático en Colombia. In Proc. XXIII Latin American Hydraulics Meeting, IAHS, Cartagena, Colombia, Septembrer

Oster, R. (1979). Las precipitaciones en Colombia. Colombia Geográfica 6, 5-147

O'gorman, P. A. and Schneider, T. (2009). Scaling of precipitation extremes over a wide range of climates simulated with an idealized gcm. Journal of Climate 22, 5676-5685

Pabón, J. D. (2005). Escenarios de cambio climático para territorio Colombiano. Documento INAPPDF-B

Pabón, J. D. (2009). El cambio climático global y su manifestación en Colombia. Cuadernos de Geografía: Revista Colombiana de Geografía 12, 111-119

Peterson, T. (2005). Climate change indices. WMO Bulletin 54, 83-86

Poveda, G., Álvarez, D. M., and Rueda, Ó. A. (2011). Hydro-climatic variability over the Andes of Colombia associated with ENSO: a review of climatic processes and their impact on one of the earth 's most important biodiversity hotspots. Climate Dynamics 36, 2233-2249

Poveda, G., Jaramillo, L., and Vallejo, L. F. (2014). Seasonal precipitation patterns along pathways of South American low-level jets and aerial rivers. Water Resources Research 50, 98-118. doi:10.1002/ 2013WR014087

Poveda, G. and Mesa, O. J. (1997). Feedbacks between hydrological processes in tropical South America and large-scale ocean-atmospheric phenomena. Journal of Climate 10, 2690-2702

Quintana-Gomez, R. A. (1999). Trends of maximum and minimum temperatures in northern South America. Journal of Climate 12, 2104-2112 
457 458 459 460 461 462 463 464 465 466 467 468 469 470 471 472 473 474 475 476 477 478 479 480 481 482 483 484 485 486 487 488 489 490 491 492 493 494 495 496 497 498

Rabatel, A., Francou, B., Soruco, A., Gomez, J., Cáceres, B., Ceballos, J., et al. (2013). Current state of glaciers in the tropical andes: a multi-century perspective on glacier evolution and climate change. The Cryosphere 7, 81-102

Ruiz, D., Moreno, H. A., Gutiérrez, M. E., and Zapata, P. A. (2008). Changing climate and endangered high mountain ecosystems in Colombia. Science of The Total Environment 398, 122-132. doi:10.1016/j. scitotenv.2008.02.038

Ruiz, J. F. (2007). Escenarios de cambio climático, algunos modelos y resultados de lluvia para Colombia bajo el escenario A1B. Nota Técnica. Tech. rep., IDEAM - METEO/003-2007

Ruiz, J. F. (2010). Cambio climático en temperatura, precipitación y humedad relativa para Colombia usando modelos meteorológicos de alta resolución. Panorama 2011 - 2100. Tech. rep., IDEAM Nota técnica 005/2010

Salazar, J. F. (2011). Regulación biótica del ciclo hidrológico en múltiples escalas. Ph.D. thesis, PhD thesis. Universidad Nacional de Colombia. Medellín

Sen, P. K. (1968). Estimates of the Regression Coefficient Based on Kendall's Tau. Journal of the American Statistical Association 63, 1379. doi:10.2307/2285891

Smith, R., Poveda, G., Mesa, O., Pérez, C., and Ruiz, C. (1996). En búsqueda de señales del cambio climático en Colombia. In IV Congreso Colombiano de Meteorología, Sociedad Colombiana de Meteorología, Bogotá

Snow, J. (1976). The Climate of Northern South America. In World survey of climatology Volume 12: Climates of Central and South America, ed. W. Schwerdtfeger (Amsterdam, Netherlands: Elsevier), chap. 6. 295-403

Soden, B. J. and Held, I. M. (2006). An assessment of climate feedbacks in coupled ocean-atmosphere models. Journal of Climate 19, 3354-3360

Stevens, B., Bony, S., et al. (2013). What are climate models missing. Science 340, 1053-1054

Urán, J. D. (2015). Cambios en los valores extremos de precipitación en regiones tropicales asociados a cambio climático. Master's thesis, Posgrado en Aprovechamiento de Recursos Hidráulicos. Universidad Nacional de Colombia Sede Medellín

Urrea, V. (2017). Variabilidad espacial y temporal del ciclo anual de lluvia en Colombia. Master thesis in water resources engineering, Universidad Nacional de Colombia, Medellín

Urrea, V., Ochoa, A., and Mesa, O. (2016). Validación de la base de datos de precipitación CHIRPS para Colombia a escala diaria, mensual y anual en el período 1981-2014. In XXVII Congreso Latinoamericano de Hidráulica (Lima, Perú: IAHS), 11

Urrea, V., Ochoa, A., and Mesa, O. (2019). Seasonality of Rainfall in Colombia. Water Resources Research doi:10.1029/2018WR023316

von Storch, H. (1995). Misuses of Statistical Analysis in Climate Research. In Analysis of Climate Variability: Applications of Statistical Techniques, eds. H. von Storch and A. Navarra (Berlin: SpringerVerlag), chap. 2. 11-26

Vuille, M., Bradley, R. S., Werner, M., and Keimig, F. (2003). 20th century climate change in the tropical andes: observations and model results. In Climate variability and change in high elevation regions: past, present \& future (Springer). 75-99

Wentz, F. J., Ricciardulli, L., Hilburn, K., and Mears, C. (2007). How much more rain will global warming bring? Science 317, 233-235 